\title{
Peertechz
}

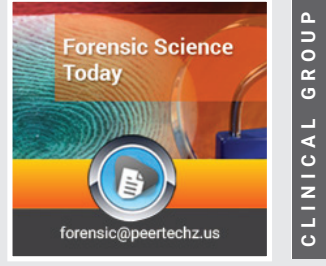

Forensic Science aosurycess

Research Article

\section{Criminological aspects of rape}

\section{Siniša Franjić*}

Independent Researcher, Europe

Received: 16 July, 2021

Accepted: 23 July, 2021

Published: 24 July, 2021

*Corresponding author: Siniša Franjić, Independent Researcher, Europe, E-mail: sinisa.franjic@gmail.com

Keywords: Rape; Criminology; Sexual violence; Law https://www.peertechzpublications.com

Check for updates

\begin{abstract}
Rape is a type of sexual assault that usually involves sexual intercourse or another form of sexual penetration without the consent of the victim. The act can be committed by physical force, threat and abuse of power. The act may also be committed against a person who is unable to give valid consent, such as one who is unconscious, disabled, has intellectual disabilities or is a juvenile.
\end{abstract}

\section{Introduction}

Rape (from the Latin rapere, to take by force) is defined in common law as "the carnal knowledge of a female forcibly and against her will." It is one of the most loathed, misunderstood, and frightening crimes [1]. Under traditional common-law definitions, rape involves nonconsensual sexual intercourse that a male performs against a female he is neither married to nor cohabitating with. There are of course other forms of sexual assault, including male on male, female on female, and female on male sexual assaults, but these are not considered within the traditional definition of rape. However, recognizing changing contemporary standards, almost every state has now revised their rape statutes, making them gender neutral. In addition, states now recognize that rape can occur among married couples and people who previously have been sexually intimate.

Traditionally, rape - non-consensual sexual intercourse - is regarded as a rare event committed by an abnormal or psychopathic stranger [2]. A violent sexual attackby an unknown male leaping out from the bushes captures the stereotype. Today, rape is likely to be seen as less rare, commonplace even, often committed by known, 'normal' men, and able to take a variety of forms, including that associated with the consensual activity of dating. In terms of explaining the causes of rape there has been a shift from the traditional individualistic focus - identifying the psychological/behavioural profiles of convicted rapists and their differences from normal men - to a focus on the social factors that encourage the denigration of women and thus render them 'rapeable' objects.

\section{History}

Rape has been a recognized crime throughout history [1]. It has been the subject of art, literature, film, and theater. Paintings such as the Rape of the Sabine Women by Nicolas Poussin, novels such as Clarissa by Samuel Richardson, poems such as The Rape of Lucrece by William Shakespeare, and films such as The Accused and The Last House on the Left have sexual violence as their central theme.

In early civilization rape was common. Men staked a claim of ownership on women by forcibly abducting and raping them. This practice led to males' solidification of power and their historical domination of women. Under Babylonian and Hebraic law, the rape of a virgin was a crime punishable by death. However, if the victim was married, then both she and her attacker were considered equally to blame, and unless her husband intervened, both were put to death.

During the Middle Ages, it was common for ambitious men to abduct and rape wealthy women in an effort to force them into marriage. The practice of "heiress stealing" illustrates how feudal law gave little thought or protection to women and equated them with property. Only in the late fifteenth century, after a monetary economy developed, was forcible sex outlawed. Thereafter, the violation of a virgin caused an economic hardship on her family, who expected a significant dowry for her hand in marriage. However, the law only applied to the wealthy; peasant women and married women were not considered rape victims until well into the sixteenth century. The Christian condemnation of sex during this period was also a denunciation of women as evil, having lust in their hearts, 
and redeemable only by motherhood. A woman who was raped was almost automatically suspected of contributing to her attack.

\section{Offense}

While the overwhelming percentage of rape victims are female, thousands of men report being sexually assaulted each year [1]. One significant difference: while women most often are attacked by strangers, almost every male rape involve a friend or acquaintance.

Population density influences the rape rate. Metropolitan areas today have rape rates significantly higher than rural areas; nonetheless, urban areas have experienced a much greater drop in rape reports than rural areas. The police make arrests in slightly more than half of all reported rape offenses. Of the offenders arrested, typically about half are under 25 years of age, and about two-thirds are white. The racial and age pattern of rape arrests has been fairly consistent for some time. Finally, rape is a warm-weather crime-most incidents occur during July and August, with the lowest rates occurring during December, January, and February.

Why is rape, one of the most serious violent crimes, also one of the most under-reported? Many victims fail to report rapes because they are embarrassed, believe nothing can be done, or blame themselves. Some victims of sexual assaults may even question whether they have really been raped; research indicates that when the assault involves an acquaintance, such as a boyfriend, and the victim had been drinking or taking drugs, they are unlikely to label their situations as being a "real" rape. Similarly, if the assault involved oral or digital sex it was less likely to be labeled a "real" rape. Women are more likely to report rape when it is committed by a stranger who uses a weapon or causes physical injury, or when the rape occurred in a public place-or if at home, was the result of "home blitz" (in which an attacker broke in or entered without permission). Therefore it is likely that many acquaintance rapes and date rapes go unreported.

Clearly, understanding the social context is the first step toward defining crime [3]. Consider sexual behavior as an example. Sexual intercourse with a minor, or statutory rape, is in the United States universally agreed to be a crime-that is, until we consider the social context. On closer inspection, legally defined rape is not universally condemned. For example, sexually active boys and girls under the age of legal consent often do not consider themselves raped. In previous historical eras, adolescents of the same age were often married and shared the rights of adults. In this same historical era, husbands could not "rape" their spouses, though they could force themselves on unwilling wives. Under old German law, an act of sexual intercourse with a woman would be considered "as rape only if it was committed against a respectable women, but not a 'vagrant woman'". Whether the physical act is condemned depends on the social and historical context and on the definition of rape. For example, if parents give permission to marry, two sexually active teens are no longer committing "rape," though their physical actions (intercourse) and circumstances (age) are the same. Rape laws have historically had a gender bias as well. Young girls have traditionally been treated much more harshly "by the law" than are young boys. The social reaction to sexual activity and prowess continues to reflect gender bias.

Furthermore, whether an issue becomes a public harm depends on a group's ability to turn private concerns into public issues or their skills at moral entrepreneurship. This is the ability to whip up moral consensus around an issue that affects some individuals or a minority and to recruit support from the majority by convincing them it is in their interest to support the issue, too. Creating a public harm often involves identifying and signifying offensive behavior and then attempting to influence legislators to ban it officially.

When using niche construction to explain rape, greater attention is paid to the causal and independent role of culture and the physical and social environments in which individuals develop [4]. There is less emphasis on discrete mental modules and more on the facilitative influence of social and cultural capital. The three types of inheritancegenetic, cultural, and ecological-are hypothesized to make independent contributions to mating behavior and the underlying mechanisms that generate specific sexual tactics. An illustration of a genetic predisposition might be males' hypothesized tendency to seek impersonal sex and to attempt to control females. An example of a relevant cultural process might be the portrayal of females as sexual objects and males as sexually entitled to have sex when and where they want. A possible ecological process could be the physical segregation of males and females at school and the workplace leaving men with minimal opportunities to acquire more realistic understandings of women's needs and preferences. Thus an individual could enter the mating domain with several possible combinations of the above sets of three factors, resulting in varying degrees of rape-proneness. For some males, the genetic predisposition (origins) toward sexual promiscuity (i.e., males consistently look for copulation opportunities while females are more oriented toward choosiness and long term mate selection) might interact with a mating learning environment (life history or developmental cause) in which females are routinely ridiculed and presented as inferior, and a culture in which they are not valued and are underrepresented in positions of power and influence. In this situation, a male could hold a schema portraying woman as always sexually available (proximal mechanism).

\section{Sexual violence}

Sexual violence, including forced or coerced sex, attempted forced sex, or unwanted sexual touching, is often excluded from studies of partner violence, especially among adolescents [5]. This form of violence, however, is neither uncommon nor insignificant and adolescence is a particu larly high-risk time for sexual violence. From childhood to adulthood, the highest risk of sexual violence among females occurs during mid-adolescence, from the ages of 14 to 18 . Unlike physical and psychological violence, the gender breakdown regarding sexual violence is not symmetric. Females are far more likely 
than males to be victims of sexual violence and males are perpetrators more often than females. Available data comes from many studies that ask specifically about "forced sexual activity" or "rape." Sexual violence, however, includes coerced and unwanted sexual activity that is not considered, or stops short of, forced sex or rape. Although some coerced or unwanted sexual activity or pressure may fail to meet legal standards of completed rape, the meaning and impact of such violence may be no less significant for the victim. Limiting measurement to more narrow terms, therefore, is both arbitrary and misleading. Because of these limits, very little is known about the true rates of coercive or forced sexual activity. This lack of data leads to insufficient tools to effectively intervene with young women in relationships at risk for violence.

\section{UCR}

Police measures of crime form the basis for the FBI's Uniform Crime Reports (UCR), a data series that has been collected since 1930 and has been widely used by criminal justice researchers [6]. But certain characteristics and procedures related to the UCR affect its suitability as a measure of crime. Most of our comments highlight shortcomings in this regard, but keep in mind that the UCR is and will continue to be a very useful measure for researchers and public officials.

The UCR does not even try to count all crimes reported to police. What are referred to as Part I offenses are counted if these offenses are reported to police (and recorded by police). Part I offenses include murder and non-negligent manslaughter, forcible rape, robbery, aggravated assault, burglary, larcenytheft, and motor vehicle theft. Other offenses, referred to as Part II crimes, are counted only if a person has been arrested and charged with a crime. The UCR therefore does not include such offenses as shoplifting, drug sale or use, fraud, prostitution, simple assault, vandalism, receiving stolen property, and all other nontraffic offenses unless someone is arrested. This means that a large number of crimes reported to police are not measured in the UCR.

Another source of measurement error in the UCR is produced by the hierarchy rule used by police agencies and the FBI to classify crimes. Under the hierarchy rule, if multiple crimes are committed in a single incident, only the most serious is counted in the UCR. For example, if a burglar breaks into a home, rapes one of the occupants, and flees in the homeowner's car, at least three crimes are committed-burglary, rape, and vehicle theft. Under the FBI hierarchy rule, however, only the most serious crime, rape, is counted in the UCR, even though the offender could be charged with all three offenses.

\section{Statistics}

Rape actually victimizes 200,000 women every year for an incidence of 1 sexual assault per 1000 citizens; this is a very conservative statistic from actual reports and arrests [7]. Posttraumatic stress disorder will occur in $80 \%$ of the victims. Psychopharmacology is promising for the treatment of sexual violence, but, until proven as a preventive tool in sexual violence, presentence diagnostics must be restored within the criminal justice system in order to separate psychopaths from less malignant sexual offenders. Certainty of sentencing is of little value without certainty of investigation and prosecution, which cannot replace diligent presentence investigation. Correctional booking offices are processing clinical cases in numbers approaching any point of entry due to deinstitutionalization and criminalization of the mentally ill and drug dependent citizens. The knowledge of predicting dangerousness is advanced, although, like all of medicine, far from perfected. Still, nothing is currently being done to make the diagnostic distinction, crucial for incarceration and probation. Consequently, thousands of sexual assaults occur that could otherwise be prevented. Furthermore, nearly $50 \%$ of assailants are either well known or actually dating the victim at the time of offense. Such statistical knowledge about this frequent and destructive offense places rape within the context of relational adjustment, likely presenting, as does domestic violence, with nonviolent manifestations at a point of entry to the health-care system.

\section{Law}

Unlike other crime victims, women may find that their claim of sexual assault is greeted with some skepticism by police and court personnel [1]. They will soon find they have to prove that they did not engage in sex only to have remorse afterwards. Police officers may be hesitant to make arrests and testify in court when the alleged assaults do not yield obvious signs of violence or struggle (presumably showing the victim strenuously resisted the attack). However, police and courts are now becoming more sensitive to the plight of rape victims and are just as likely to investigate acquaintance rapes as they are aggravated rapes involving multiple offenders, weapons, and victim injuries. In some jurisdictions, the justice system takes all rape cases seriously and does not ignore those in which victim and attacker have had a prior relationship or those that did not involve serious injury.

Proving guilt in a rape case is extremely challenging for prosecutors. Although the law does not recognize it, jurors are sometimes swayed by the insinuation that the rape was victim precipitated; thus the blame is shifted from rapist to victim. To get a conviction, prosecutors must establish that the act was forced and violent and that no question of voluntary compliance exists. They may be reluctant to prosecute cases where they have questions about the victim's moral character or if they believe that the victim's demeanor and attitude (i.e., they were dressed provocatively) will turn off the jury and undermine the chance of conviction. Prosecutors may be more willing to bring charges in interracial rape cases because they know that juries are more likely to believe victims and convict defendants in cases involving interracial rape than in intraracial rapes.

\section{Criminology}

Criminology is the study of crime, as indicated by the formative Latin terms crimin (accusation or guilt) and -ology (study of) [8]. As an intellectual domain, criminology comprises contributions from multiple academic disciplines, including psychology, biology, anthropology, law, and, especially, 
sociology. Although the defining statements of criminology are rooted across these diverse areas, contemporary criminology is becoming ever more intertwined with still additional sciences and professional fields such as geography, social work, and public health.

This plurality of influences, often referred to as multidisciplinarity, is altogether logical given the complex subject matter and diverse nature of crime. Scholarly attention to crime from various perspectives allows for an extensive range of research questions to be addressed, making possible a fuller understanding of the criminal mind, the nature of crime, and social control processes. Legal scholarship, for example, ranges from philosophical attention to social justice issues to technocratic factors determinant of case outcome. Alternatively, psychology approaches the topic of crime with a focus on individual-level maladjustment and behavioral abnormality. Sociological criminology differs still by concentrating on the multiple causes and nature of crime, as well as society's reaction to it.

The individuals who study crime, criminologists, engage research on virtually every imaginable aspect of illegality and society's reactions to it, ranging from the development of theories of crime causation, the roles and uses of social control (e.g., police, courts, and corrections), crime prevention, and victimization. Of course, criminologists have also developed substantial knowledge bases on specific offenses, which are often categorized as (a) crimes against property (e.g., burglary, theft, robbery, and shoplifting); (b) crimes against a person (e.g., homicide, assault, and rape); (c) morality/social order crimes (e.g., gambling, prostitution, substance offenses, vandalism); and now (d) technology crime/cybercrime, which overlaps with and often facilitates crime in each of the other categories. The collective basic knowledge that criminologists have generated through the scientific process has great potential for informing social policy and criminal justice practice through enhancement of the effectiveness and efficiency of prevention, intervention, enforcement, and rehabilitative strategies and practices in the 21st century.

\section{Criminal justice}

Four aspects of criminal justice interact reciprocally and sometimes dialectically: crime, criminality, criminalization, and policy and practice [9]. Studies of crime include its ontology, prevalence, incidence, and variation. Who commits crimes, when, how, and why are the questions relevant to criminality. Examinations of criminalization ask how a society comes to designate something as criminal, whether that something is a person, a thing, or a behavior. Policy studies analyze those organizations, usually governmental, that administer criminal law-cops, courts, and corrections.

Since the foremost task of theory is to tackle explanation, theories about criminal justice should explain one or more of its four aspects. The more useful theories explain all four aspects along with how those aspects affect each other. Too often crime theory predominates. This kind of crime theory makes unwarranted and unquestioned assumptions, especially about the definitions of crime, how institutions shape crime, and how policies create a criminal class. By way of illustration, most theorizing by criminologists and scholars of criminal justice offers accounts of street crime-robbery, rape, murder, theft, and so forth. Few, if any, theories treat war crimes, terrorism, and crimes of high finance in the same way.

It is often said that rape victims are victimized twiceonce by the actual rapists and again by the criminal justice system if they decide to report their rape [10]. There is often a stark difference between what is "good" for the victim and the goals and organizational nature of the criminal justice system. The primary goal of police and prosecutors is to prove beyond a reasonable doubt that a crime occurred. The successful prosecution of a case hinges on physical evidence and corroborating witnesses. In most rape and sexual assault cases, the sole witness is the victim. The process begins with reporting the crime to the police.

The hospital is the key institution for rape investigation, because this is often the first place that victims go after a sexual assault. The hospital is responsible for a medical examination and the collection of physical evidence. Physicians and hospital staff have been called the "reluctant partners" in systems that work with rape victims. Rape victims are often not viewed as "real" patients (especially if there is no physical injury), and doctors are reluctant to perform rape exams (they are long and intrusive) and to testify in court. Even where physical evidence confirms sexual relations, it often cannot speak to whether the sex was consensual.

The primary role of police officers is to "build a good case." Police officers, attempting to get a thorough and clear statement, often come across as "interrogating" the victim. Accordingly, victims often feel as though the police do not believe their story. Prosecutors generally strive to secure a conviction that results in punishment appropriate to the level of harm caused by the crime. Prosecutors represent the state rather than the victim and generally prefer plea bargaining (a sure conviction) to trial. Research suggests that prosecutors are more likely to either dismiss or plea bargain rape cases than other types of criminal cases. There is also evidence that prosecutors try to find discrepancies in a victim's statements, determine if the victim had ulterior motives for alleging rape, and see if the victim fits the criteria for a "typical" victim when deciding whether to charge a rape case. Prosecutors may also be more leery about accepting the victim's testimony as the truth and may require the victim to take a polygraph test. Prosecutors justify these actions by noting that coercion is difficult to prove, which makes it hard to secure convictions for rape and sexual assault cases.

\section{Conclusion}

Rape is defined in most jurisdictions as sexual intercourse, or other forms of sexual penetration committed by the perpetrator against the victim without her consent. Lack of consent is key to the definition of rape. Lack of consent may be the result of coercion by the perpetrator. Coercion is a situation where a person is threatened by force or violence, 
and can result in the absence of objections to sexual activities. Coercion can be real or threatening force or violence against the victim or someone close to the victim. Even blackmail can be coercive. Abuse of power can constitute coercion. Rape is the most difficult form of sexual violence that leaves long-lasting consequences. It is one of the extremely difficult and traumatic experiences with heavy consequences for the victims. During criminal investigation, evidence is gathered that can confirm rape; as a rule, evidence can be found in clothes, smears of buccal, vaginal and rectal mucosa; hair and pubic hair samples; material under the nails; blood and saliva samples and, if available, semen. There is often no evidence or they are indeterminate after showering, changing clothes, rinsing the vagina. Each of the samples is kept as separate evidence, marked, dated, stamped and retained until handed over to another official who will undertake all the predicted activities with a purpose of further criminal processing.

\section{References}

1. Siegel L (2012) Criminology. Eleventh Edition, Wadsworth, Cengage Learning, Belmont, USA 339-343. Link: https://bit.ly/3iBKk4w

2. Gadd D, Jefferson $T$ (2007) Psychosocial Criminology - An Introduction. SAGE Publications Ltd, London, UK 69. Link: https://bit.ly/3x02jXe

3. Lanier MM, Henry S (2010) Essential Criminology. Third Edition", Westview Press, Boulder, USA Journal of Theoretical and Philosophical Criminology 2 : 67-70. Link: https://bit.ly/36UCOMr
4. Durrant R, Ward T (2015) Evolutionary Criminology - Towards a Comprehensive Explanation of Crime, Academic Press, Elsevier, London, UK 150-151. Link: https://bit.ly/3zGvjp1

5. Dichter ME, Cederbaum JA, Teitelman AM (2010) The Gendering of Violence in Intimate Relationships - How Violence Makes Sex Less Safe for Girls. In Chesney-Lind, M.; Jones, N. (eds): Fighting for Girls - New Perspectives on Gender and Violence. State University of New York Press, Albany, USA 86. Link: https://bit.ly/3hYML1Z

6. Maxfield MG, Babbie E (2009) Basics of Research Methods for Criminal Justice and Criminology. Wadsworth, Cengage Learning, Belmont, USA 99.

7. Liebert JA, Birnes WJ (2017) Psychiatric Criminology - A Roadmap for Rapid Assessment. CRC Press, Taylor \& Francis Group, Boca Raton, USA 66-67. Link: https://bit.ly/3iDssWH

8. Miller JM (2009) Criminology as Social Science - Paradigmatic Resiliency and Shift in the $21^{\text {st }}$ Century. In Miller, J. M. (Ed): 21 st Century Criminology - A Reference Handbook. SAGE Publications, Inc., Thousand Oaks, USA 2. Link: https://bit.ly/3zmYaOK

9. Skoll GR (2009) Contemporary Criminology and Criminal Justice Theory Evaluating Justice Systems in Capitalist Societies. Palgrave Macmillan, New York, USA 2. Link: https://bit.ly/3kJPVs9

10. Vito GF, Maahs JR (2017) Criminology - Theory, Research, and Policy. Fourth Edition. Jones \& Bartlett Learning, LLC, Burlington, USA 226. Link: https://bit.ly/3ByXeZp
Discover a bigger Impact and Visibility of your article publication with

\section{Peertechz Publications}

Copyright: (c) 2021 Franjić S. This is an open-access article distributed under the terms of the Creative Commons Attribution License, which permits unrestricted use, distribution, and reproduction in any medium, provided the original author and source are credited. 